\title{
Factors Affecting Public Non-compliance With Large-scale Social Restrictions to Control COVID-19 Transmission in Greater Jakarta, Indonesia
}

\author{
Bunga Christitha Rosha, Indri Yunita Suryaputri, Irlina Raswanti Irawan, Prisca Petty Arfines, Agus Triwinarto \\ Centre for Research and Development of Public Health Efforts, National Institute of Health Research and Development (NIHRD), Central Jakarta, \\ Indonesia
}

Objectives: The Indonesian government issued large-scale social restrictions (called Pembatasan Sosial Berskala Besar, or PSBB) at the beginning of the coronavirus disease 2019 (COVID-19) pandemic to control the spread of COVID-19 in Jakarta, Bogor, Depok, Tangerang, and Bekasi (Greater Jakarta). Public compliance poses a challenge when implementing large-scale social restrictions, and various factors have contributed to public non-compliance with the regulation. This study aimed to determine the degree of non-compliance and identify the factors that contributed to public non-compliance with the PSBB in Greater Jakarta, Indonesia.

Methods: This was a quantitative study with a cross-sectional design. A total of 839 residents of Greater Jakarta participated in this study. Data were collected online using a Google Form, and convenience sampling was undertaken. Univariate and multivariate analyses were performed to explore the relationships between public non-compliance with the PSBB regulation and socio-demographic variables, respondents' opinion of the PSBB, and social capital.

Results: A total of $22.6 \%$ of subjects reported participating in activities that did not comply with the PSBB. The variables that most affected non-compliance with the PSBB were age, gender, income, opinion of the PSBB, and social capital.

Conclusions: Strengthening social capital and providing information about COVID-19 prevention measures, such as washing one's hands with soap, wearing masks properly, and maintaining social distancing, is essential. Robust public understanding will foster trust and cooperation with regard to COVID-19 prevention efforts and provide a basis for mutual agreement regarding rules/penalties.

Key words: Physical distancing, Social capital, COVID-19, Pandemic, Indonesia

\section{INTRODUCTION}

Received: February 24, 2021 Accepted: May 24, 2021

Corresponding author: Bunga Christitha Rosha

Centre for Research and Development of Public Health Efforts, National Institute of Health Research and Development (NIHRD),

JI. Percetakan Negara, Central Jakarta 10560, Indonesia

E-mail: bunga.puslit3@gmail.com

This is an Open Access article distributed under the terms of the Creative Commons Attribution Non-Commercial License (https://creativecommons.org/licenses/bync/4.0// which permits unrestricted non-commercial use, distribution, and reproduction in any medium, provided the original work is properly cited.
By early 2020, coronavirus disease 2019 (COVID-19) had spread to almost every country in the world, which led the World Health Organization (WHO) to classify COVID-19 as a pandemic [1]. By the end of January 2021, the number of people infected with COVID-19 in Indonesia reached 1 million people [2]. To reduce the transmission of COVID-19, the WHO issued comprehensive guidelines that included practicing social/physical distancing [3]. In April 2020, the Indonesian government issued Government Regulation No. 21 of 2020-a set 
of large-scale social restrictions (called Pembatasan Sosial Berskala Besar, referred to from here on as "PSBB") issued in an attempt to control the spread of COVID-19. The PSBB included measures restricting certain activities in public areas such as schools, workplaces, and public transportation facilities that were considered high-risk for the spread of COVID-19. The restrictions also applied to all activities that could potentially endanger Indonesia's defense and security $[4,5]$. The PSBB was first implemented by the Special Capital District of Jakarta in April 2020 and later implemented in surrounding satellite areas (Greater Jakarta) [6].

Public participation and compliance are required for the successful implementation of the PSBB. However, a recent study found that public compliance remains low. The results of a recent survey in Indonesia showed that $58.6 \%$ of respondents found it difficult to practice physical distancing [7]. Failure to comply with social distancing recommendations is the primary cause of the massive spread of COVID-19 across regions and can result in a steep increase in the number of active cases and COVID-19-related deaths. Several factors may influence public compliance, such as public awareness of the restrictions, the severity of penalties for non-compliance, public support and trust of regulatory authorities, and economic and psychological conditions [8]. Other factors related to adherence to health-related precautions during the COVID-19 pandemic include socio-cultural factors, income, occupation, social capital, and gender [9]. Some of these factors are modifiable variables, such as social capital, knowledge of the PSBB, and opinion of the PSBB, while other variables are not modifiable, including age, gender, occupation, income, and education level, all of which are known to influence individuals' health status [10].

Strategies should be undertaken to address modifiable variables such as individuals' beliefs and social factors to ensure that people comply with regulations intended to reduce the transmission of COVID-19. One of the social factors that affect compliance with regulations within communities is social capital. Social capital plays an important role in COVID-19 prevention in communities. Social capital refers to the behaviors of individuals in the context of their communities and their relationships with community members, which include collective customs, norms, public trust, and social networks, to achieve common goals $[11,12]$. In public health, social capital has been found by researchers to be a variable that improves health outcomes and can serve as a framework for evaluating public health interventions [13]. Strong social capital in communities is important for successfully implementing public policies such as the PSBB examined in this study. Mutual trust, mutual respect, community awareness, cooperation between community members, adherence to existing rules and customs, public disclosure of information, and examples of model behavior from policy-makers and leaders will nurture a strong sense of collective motivation in communities which leads to collective action. However, if a community has weak social capital, it can reduce public cooperation, raise suspicions, enable violation of regulations, and undermine efforts made to prevent the spread of COVID-19 [14]. In this study, we aimed to determine the degree of public non-compliance with the PSBB and examined the factors affecting community non-compliance in Greater Jakarta, Indonesia.

\section{METHODS}

\section{Study Design}

This is a quantitative study with a cross-sectional design for which questionnaires were distributed online using a Google Form. The inclusion criteria included residence in 1 of 5 cities (Jakarta, Bogor, Depok, Tangerang, or Bekasi), being aged 15 or above, and having access to social media (WhatsApp/Facebook). Non-probability sampling was conducted using the convenience sampling method.

\section{Sampling and Data Collection Procedures}

Data from a total of 900 respondents were entered into a database. After performing data cleaning, the final number of participants involved in the study was 839 people. Duplication checking was carried out based on matching names and responses (Figure 1).

\section{Study Variables}

The dependent variable in this study was non-compliance with the PSBB, which was measured based on participants' responses to 7 questions related to working or studying from home, worshipping at home, attending celebrations/parties, spending time with friends outside the home, attending gatherings, physical distancing on public transportation, and travel outside of one's town. The cut-off point used to determine compliance or non-compliance with the PSBB was the average/mean value of 6 points, with scores of $\geq 6$ points indicating compliance and scores of $<6$ indicating non-compliance. 


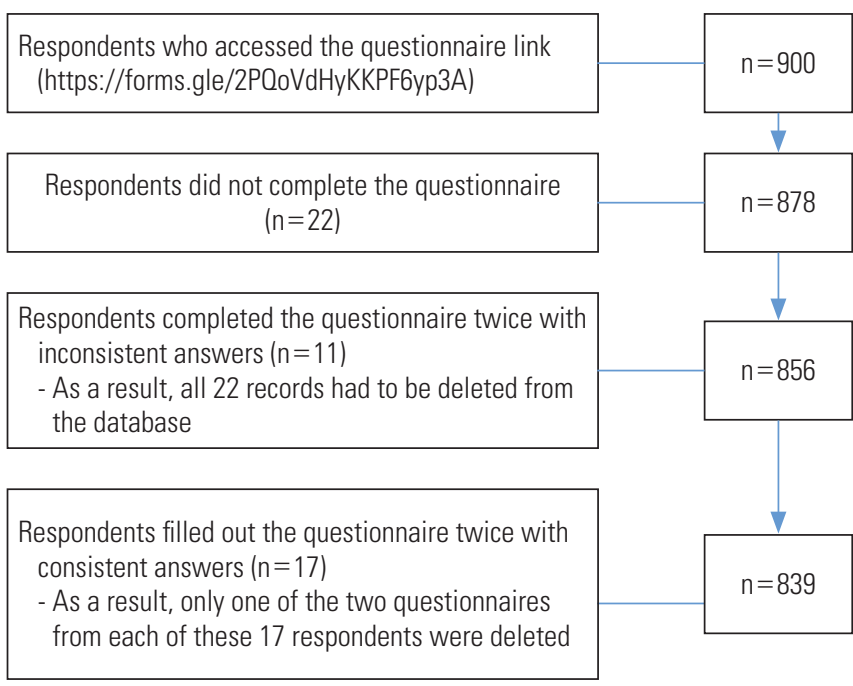

Figure 1. Flow diagram for the inclusion of study participants.

The independent variables were socio-demographic characteristics such as age (classified as participants from the ages of 15 to 35 and participants $>35$ years old), gender (women and men), education level (high school graduates and above or non-high school graduates), occupation (those with regular income, such as private and government employees, or those with irregular income, such as laborers, merchants, motorcycle or taxi drivers, farmers, fishermen, respondents who were unemployed due to the COVID-19 pandemic, household assistants, or students), place of residence (city or district), residence type (housing complex or non-housing complex), the level of involvement of community leaders as providers of information (sufficient or insufficient), and if participants received cash or non-cash social assistance from the government after being infected with COVID-19 (beneficiaries or non-beneficiaries). The other variables included in this study were knowledge and opinion of the PSBB. There were 3 groups of questions related to one's knowledge of the PSBB, opinion of the PSBB, and behavior. Participants' level of knowledge was assessed using 10 questions for which respondents were categorized as "knowledgeable" if they scored $\geq 8$ points and "compliant with the PSBB" if they scored $\geq 6$ points. They were considered noncompliant if they scored $<6$ points. In addition, the respondents' opinions of the PSBB were measured based on 8 questions, and they were considered to have a positive opinion if they scored $\geq 6$ points. The questions about participants' opinions asked about restrictions to movements outside the home, prevention of virus transmission, penalties for violating the
PSBB, social assistance offered by the government, one's sense of his or her susceptibility to COVID-19 infection, the implementation of restrictions, limitations to public transportation capacity, and support for implementing restrictions.

The other independent variable in this study was social capital, which was assessed by asking respondents about their opinions regarding community trust, cooperation, and the enforcement of penalties for non-compliance. Trust-related questions asked respondents whether he or she believed that the PSBB made the response to COVID-19 more effective, had trust in community leaders to be able to manage the community response to the pandemic, had trust in community leaders to implement policies, and believed in the community's ability to implement social/physical distancing. Respondents were also asked cooperation-related questions related to cooperation in helping affected communities, cooperation between community leaders and the public, and cooperation between communities, community leaders, and health workers. Lastly, respondents were asked if their community leaders effectively communicated that non-compliance with the PSBB was considered a violation of community rights and that penalties would be issued to offenders. Scores were calculated for each of the 3 indicators of social capital. An indicator was considered to be positive if the mean value of the total score for that indicator was equal to or greater than 2. Otherwise, it was considered to be negative. Social capital was considered strong if a minimum of 2 indicators were positive and weak if fewer than 2 indicators were positive.

\section{Statistical Analysis}

Univariate, bivariate, and multivariate analyses were conducted for this study. Univariate analysis was intended to describe the distribution of data, meaning the frequency of each independent and dependent variable. Bivariate analysis was performed by constructing a $2 \times 2$ table between each independent variable and dependent variable to obtain the odds ratio (OR). The Pearson chi-square test was conducted, and any variables found to be statistically significant at the level of 0.25 were also included in the multivariate logistic regression model. Subsequently, the backward elimination method was used. The regression analysis results were presented as ORs and adjusted ORs with $95 \%$ confidence intervals (Cls). Data analysis was performed using IBM SPSS version 20.0 (IBM Corp., Armonk, NY, USA). 


\section{Ethics Statement}

Ethical approval for this study was obtained from the $\mathrm{Na}$ tional Health Research Ethics Commission of the National Institute of Health Research and Development (LB.02.01/2/KE. $311 / 2020$ ). Respondents were permitted to refuse to participate in the study after reading the informed consent form. To maintain confidentiality, no personal identifiers were included on the questionnaire and the answer sheets.

Table 1. Participants' characteristics

\begin{tabular}{|c|c|}
\hline Characteristics & n (\%) \\
\hline \multicolumn{2}{|l|}{ Place of residence } \\
\hline City & $659(78.5)$ \\
\hline District & $180(21.5)$ \\
\hline \multicolumn{2}{|l|}{ Residence type } \\
\hline Housing complex & $409(48.7)$ \\
\hline Non-housing complex & $430(51.3)$ \\
\hline \multicolumn{2}{|l|}{ Gender } \\
\hline Women & $653(77.8)$ \\
\hline Men & $186(22.2)$ \\
\hline \multicolumn{2}{|l|}{ Age (y) } \\
\hline $15-35$ & $533(63.5)$ \\
\hline$>35$ & $306(36.5)$ \\
\hline \multicolumn{2}{|l|}{ Education } \\
\hline Low & $177(21.1)$ \\
\hline Medium to high & $662(78.9)$ \\
\hline \multicolumn{2}{|l|}{ Occupation } \\
\hline Regular income & 418 (49.8) \\
\hline Irregular income & $421(50.2)$ \\
\hline \multicolumn{2}{|l|}{ Knowledge of PSBB } \\
\hline Good & $750(75.7)$ \\
\hline Poor & $89(24.3)$ \\
\hline \multicolumn{2}{|l|}{ Opinion of PSBB } \\
\hline Positive & $486(57.9)$ \\
\hline Negative & $353(42.1)$ \\
\hline \multicolumn{2}{|l|}{ Compliance with PSBB } \\
\hline Compliant & $646(77.4)$ \\
\hline Non-compliant & $189(22.6)$ \\
\hline \multicolumn{2}{|l|}{ Social capital } \\
\hline Strong & $711(84.7)$ \\
\hline Weak & $128(15.3)$ \\
\hline \multicolumn{2}{|c|}{ The role of community leaders } \\
\hline Sufficient & $544(64.8)$ \\
\hline Insufficient & $295(35.2)$ \\
\hline \multicolumn{2}{|l|}{ Social assistance } \\
\hline Beneficiaries & $77(9.2)$ \\
\hline Non-beneficiaries & 762 (90.8) \\
\hline
\end{tabular}

PSBB, large-scale social restrictions.

\section{RESULTS}

Table 1 shows the characteristics of the 839 participants included in the study. In total, $78.5 \%$ of participants lived in cities. The proportion of respondents living in housing complexes $(48.7 \%)$ and non-housing complexes (51.3\%) was similar. Nearly $78 \%$ of respondents were women. Approximately $64 \%$ of the respondents ranged from 15 years to 35 years old. About

Table 2. Compliance with the practices and associated factors (PSBB) and associated factors

\begin{tabular}{|c|c|c|c|c|}
\hline \multirow[b]{2}{*}{ Characteristics } & \multicolumn{3}{|c|}{ Compliance with the PSBB } & \multirow[b]{2}{*}{$p$-value } \\
\hline & Compliant & $\begin{array}{c}\text { Non- } \\
\text { compliant }\end{array}$ & Total & \\
\hline Place of residence & & & & 0,02 \\
\hline City & $521(79.1)$ & $138(20.9)$ & $659(100)$ & \\
\hline District & $128(71.1)$ & $52(28.9)$ & $180(100)$ & \\
\hline Residence type & & & & 0.15 \\
\hline Housing complex & $325(79.5)$ & $84(20.5)$ & 409 (100) & \\
\hline Non-housing complex & $324(75.3)$ & $106(24.7)$ & 430 (100) & \\
\hline Gender & & & & 0.01 \\
\hline Women & $518(79.3)$ & $135(20.7)$ & $653(100)$ & \\
\hline Men & $131(70.4)$ & $55(29.6)$ & $186(100)$ & \\
\hline Age (y) & & & & 0.02 \\
\hline $15-35$ & $399(74.9)$ & $134(25.1)$ & $533(100)$ & \\
\hline$>35$ & $250(81.7)$ & $56(18.3)$ & $306(100)$ & \\
\hline Education & & & & 0.82 \\
\hline Low & $138(78.0)$ & $39(22.0)$ & $177(100)$ & \\
\hline Medium to high & $511(77.2)$ & $151(22.8)$ & $662(100)$ & \\
\hline Occupation & & & & 0.01 \\
\hline Regular income & $308(73.7)$ & $110(26.3)$ & $418(100)$ & \\
\hline Irregular income & $341(81.0)$ & $80(19.0)$ & $421(100)$ & \\
\hline Knowledge of PSBB & & & & 0.56 \\
\hline Good & $578(77.1)$ & $172(22.9)$ & $750(100)$ & \\
\hline Poor & $71(79.8)$ & $18(20.2)$ & $89(100)$ & \\
\hline Opinion of PSBB & & & & 0.01 \\
\hline Positive & $390(80.2)$ & 96 (19.8) & $486(100)$ & \\
\hline Negative & $259(73.4)$ & $94(26.6)$ & $353(100)$ & \\
\hline Social capital & & & & 0.01 \\
\hline Strong (0) & $561(78.9)$ & $150(21.1)$ & $711(100)$ & \\
\hline Weak (1) & $88(68.8)$ & 40 (31.3) & $128(100)$ & \\
\hline \multicolumn{2}{|c|}{ The role of community leaders } & & & 0.37 \\
\hline Sufficient & 426 (78.3) & $118(21.7)$ & $544(100)$ & \\
\hline Insufficient & $223(75.6)$ & $72(24.4)$ & $295(100)$ & \\
\hline Social assistance & & & & 0.20 \\
\hline Beneficiaries & $64(83.1)$ & $13(16.9)$ & $77(100)$ & \\
\hline Non-beneficiaries & $585(76.8)$ & $177(23.2)$ & $762(100)$ & \\
\hline
\end{tabular}

Values are presented as number (\%).

PSBB, large-scale social restrictions. 
$79 \%$ of respondents had a medium to high education level, and almost $50 \%$ had a job with regular income. More than $76 \%$ of respondents were knowledgeable regarding the PSBB. However, only $58 \%$ of respondents had a positive opinion of PSBB practices. More than $77 \%$ of respondents were compliant with the PSBB. Additionally, nearly $85 \%$ of respondents lived in neighborhoods with strong social capital, with about $65 \%$ of respondents stating that the role of community leaders made a sufficient effort to stem COVID-19 transmission. Lastly, about 9\% of respondents reported receiving social assistance from the government.

Bivariate analysis was conducted to examine the relationship between the dependent and independent variables. The results showed that the variables with statistically significant $(p<0.05)$ associations with PSBB compliance were place of residence, gender, age, occupation, opinion of PSBB, and social capital (Table 2).

The main finding of our study was that respondents who lived in communities with weak social capital were 1.58 times less likely to comply with PSBB regulations than respondents who lived in communities with strong social capital. Among the social variables, social capital was more influential than respondents' opinions. Respondents with a negative opinion of the PSBB were 1.45 times more likely to be non-compliant than respondents whose opinion of the PSBB was positive. Respondents aged 15 years to 35 years old were 1.64 times more likely to be non-compliant than respondents older than 35 years. Men respondents were 1.63 times more likely to be non-

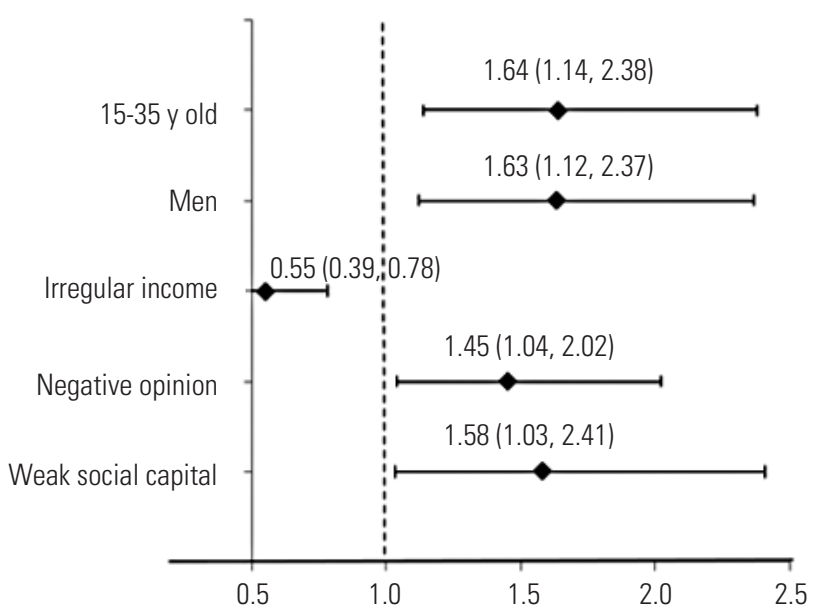

Figure 2. Factors that influenced practices and associated factors compliance. Values are presented as odds ratio (95\% confidence interval). compliant than women respondents. Respondents with irregular income were more likely to be compliant with the PSBB ( $\mathrm{OR}=0.55$ for non-compliance) than respondents who had jobs with regular income (Figure 2).

\section{DISCUSSION}

These results regarding social capital and public compliance with PSBB practices show that respondents who lived in communities with weak social capital were 1.58 times more likely to be non-compliant with the PSBB $(\mathrm{OR}, 1.58 ; 95 \% \mathrm{Cl}, 1.03$ to 2.41) than respondents who lived in communities with strong social capital. This may indicate that non-compliant behavior is a result of living in a community with weak social capital and limited information about the PSBB. Leaders in communities with weak social capital may not strictly enforce PSBB regulations, such as wearing masks or holding in-person gatherings, or issue penalties for non-compliance. In addition, communities with weak social capital tend to be less active socially and show poorer cooperation in mitigating the effects of the COVID-19 pandemic. People in these communities may not believe that COVID-19 is dangerous and do not comply with the PSBB as a result. The concept of social capital as an individual characteristic may contribute to health promotion interventions that incorporate recent knowledge about how to design interventions for social networks to meet target groups' needs. The concept of social capital as a distinct characteristic of communities provides a useful framework for policy-makers to develop community guidelines to enforce the implementation of health promotion activities. Social capital is related to the idea that a healthy social environment needs to be nurtured collectively through the active participation of community members to achieve common goals. Social capital might provide a basis for various aspects of health promotion, as it relates to human interaction, cooperation, and community action [15]. The heterogeneity of a population does not pose an obstacle to improving the status of public health with strategic utilization of social capital. A community's ability to build social networks is based on mutual trust, mutual concern, people's willingness to help other community members, adherence to shared values and norms, and proactive participation in community activities. Community matters can be addressed using collective action to solve numerous ongoing health problems [16]. Social capital gives strength to communities facing difficult times through collective norms that nur- 
ture trust among community members and help them to build large social networks. A study of the United States during the COVID-19 pandemic found that regions with high peer-to-peer trust had significantly lower mobility during the lockdown than regions where public trust levels were low [17].

Moreover, this study showed that respondents with negative opinions of PSBB guidelines were 1.45 times more likely to be non-compliant (OR, 1.45; $95 \% \mathrm{Cl}, 1.04$ to 2.02 ) than those with positive opinions. Negative opinions of the PSBB are likely due to respondents feeling like their ability to engage in public life outside their homes, such as going to work, attending a place of worship, and socializing with other people, is limited. In addition, the COVID-19 pandemic has posed many additional challenges to everyday life since working outside one's home has largely been restricted or banned, and many people have chosen not to comply or were unable to comply with this particular regulation. Though public opinion is usually related to public behavior, it can also be contradictory. A study in Italy showed that respondents who believed that stay-at-home orders would be lifted sooner than predicted were more likely to comply with regulations than those who believed the opposite [8]. Unlike before, online surveys conducted in the United Kingdom showed that public compliance with stay-at-home recommendations and lockdowns was a result of individuals' compliance with their own privately-held beliefs about the pandemic and public health, rather than simply obeying government advice during the lockdown [18]. Our findings regarding public opinion of the PSBB were also in line with an online survey conducted in the Netherlands that showed that respondents who observed strong moral constraints were more likely to comply with the Dutch government's lockdown rules [19]. Additionally, an online survey of respondents with a mean age of 16 years old in the United States showed that United States adolescents with strong senses of social responsibility showed better adherence to social distancing and hand washing policies [20].

In addition, this study found that respondents aged 15-35 years old were 1.64 times more likely to be non-compliant with the PSBB (OR, 1.64; $95 \% \mathrm{Cl}, 1.14$ to 2.38 ) than older respondents. Young people may tend to disobey lockdown regulations due to having highly active lifestyles that cause them to prioritize their work and social lives over PSBB regulations. Young people also may feel they have stronger immune systems than older people, making them less worried about $\mathrm{CO}$ VID-19 infection and leading them to continue their activities outside the home. In contrast, a survey in the United States found no significant relationship between age and social distancing compliance [21]. However, several studies have shown that age was associated with behavioral adherence during the COVID-19 pandemic. An online study in the United Kingdom have found that the highest degree of compliance to social distancing regulations was by participants aged 60 and above, followed by people aged 30-59, then people aged 18-29. Younger people tended to be less compliant with social distancing regulations in that study [22]. A survey conducted via a social media platform in the United States also showed similar results. In total, $39.8 \%$ of respondents reported that they did not comply with social distancing recommendations, with the youngest group (aged 18-31) showing the lowest level of compliance (52.4\%) [23]. Moreover, a survey in France showed significant differences in adherence to recommendations among study participants, with those in the younger age group ( $\leq 24$ years old) having lower adherence scores than those in the older age group [24]. In addition, one study found a positive association between age group and law-abiding orientation, showing that older respondents ( $>45$ years old) were more likely to practice social distancing than younger respondents. The finding that older people were more likely to practice social distancing may indicate a mediating effect; older Americans practiced social distancing more often than younger Americans, but this difference may be largely influenced by age-related differences such as awareness of, attitudes toward, and beliefs about the COVID-19 pandemic [25].

Gender can also affect behavior in society. Our study found differences in compliance according to gender, with men being 1.63 times more likely to be non-compliant with PSBB practices (OR, 1.63; 95\% Cl, 1.12 to 2.37$)$ than women. In line with our study, an online survey in 2016 in the United States showed that moral beliefs and understanding of the significance of regulations reduced the likelihood of someone violating those regulations, and different trends in responses and underlying moral issues were observed between men and women. Men and women were made different ethical judgments concerning moral issues related to compliance with regulations. In addition, gender was found to have only a moderate impact on compliance with regulations and did not directly impact compliance [26]. Another online survey from France conducted before the peak of the COVID-19 pandemic and after the lockdown found that women participants had better adherence to recommended health behaviors to pre- 
vent COVID-19 than men participants [24]. In addition, a study of 8 countries (Australia, Austria, France, Germany, Italy, New Zealand, the United Kingdom, and the United States) found that women were more likely to perceive COVID-19 as a very significant health problem and comply with public policy measures [27]. There are several possible reasons for this difference. Men are disproportionately responsible for working to support their families and may have had to continue carrying out work duties to earn money despite lockdown regulations. In addition, men may believe that they have stronger immune systems than women and are less worried about COVID-19 infection.

The results of this study also show that respondents with irregular income (laborer, merchants, motorcycle or taxi drivers, people who were unemployed due to the COVID-19 pandemic, household assistants, and students) tended to be more non-compliant with the PSBB (OR, $0.55 ; 95 \% \mathrm{Cl}, 0.39$ to 0.78$)$ than those who with jobs that generated a regular income. This finding contradicts the results of other study. A study conducted in China found that white-collar workers tended to comply with COVID-19 prevention measures in the post-pandemic period [28]. This result from our study may have been due to having a high number of respondents with jobs that generate regular income as opposed to those with irregular income. In addition, it is possible that a disproportionate number of respondents in our study with irregular income were household assistants. Since household assistants work mainly at home, they likely tended to have better compliance with the PSBB. Meanwhile, respondents who had jobs with regular income may have faced challenges when trying to comply with the PSBB since some companies or offices may have still required or allowed employees to be present in the office despite work-from-home rules.

There are limitations to this study. First, online research can only reach people with internet access and who use social media, so the distribution of respondents was limited to specific groups. An unequal distribution of respondents could lead to selection bias, which may in turn affect the generalizability of the findings. However, this study provides the following contributions: (1) identifying the correlation between PSBB compliance with respondents' perceptions and social capital in the area of Greater Jakarta; (2) providing strategic recommendations for improving public compliance with the PSBB in Greater Jakarta.

In conclusion, this study found that $22.6 \%$ of respondents did not comply with the PSBB. Factors related to PSBB compliance were age, gender, occupation, opinion of the PSBB, and social capital. This study's findings reveal an urgent need to improve community compliance to stem the transmission of COVID-19 by strengthening social capital and providing the general public with knowledge or information related to COVID-19 prevention, such as information about washing one's hands with soap, wearing masks properly, and maintaining social/physical distancing to build trust and cooperation within communities. Community-driven social efforts should be undertaken to stem the spread of COVID-19 and develop collective social agreements regarding rules and penalties.

\section{CONFLICT OF INTEREST}

The authors have no conflicts of interest associated with the material presented in this paper.

\section{FUNDING}

None.

\section{ACKNOWLEDGEMENTS}

We would like to thank the Head of Centre for Research and Development of Public Health Efforts, National Institute of Health Research and Development (NIHRD) for providing support for and the opportunity to undertake this research. We also thank the respondents who gave their time and participation in the study, and offer special thanks to Ning Sulistiyowati, SKM, M.Kes for the supervision during this study.

\section{AUTHOR CONTRIBUTIONS}

Conceptualization: BCR, AT. Data curation: BCR, PPA. Formal analysis: $B C R$. Funding acquisition: None. Methodology: $B C R$, IRI. Visualization: $B C R$, IYS. Writing - original draft: $B C R$. Writing - review \& editing: BCR, IYS, IRI, PPA, AT.

\section{ORCID}

Bunga Christitha Rosha https://orcid.org/0000-0003-29795903

Indri Yunita Suryaputri https://orcid.org/0000-0003-29826669 
Irlina Raswanti Irawan https://orcid.org/0000-0002-40207319

Prisca Petty Arfines https://orcid.org/0000-0002-5118-7536 Agus Triwinarto https://orcid.org/0000-0003-2564-6150

\section{REFERENCES}

1. Media Informasi Resmi Terkini Penyakit Infeksi Emerging. Guidelines for the prevention and control of coronavirus disease (COVID-19); 2020 [cited 2021 Jan 26]. Available from: https://covid19.kemkes.go.id/protokol-covid-19/kmk-no-hk01-07-menkes-413-2020-ttg-pedoman-pencegahan-danpengendalian-covid-19 (Indonesian).

2. Satuan Tugas Penanganan COVID-19. Situaion COVID-19 in Indonesia [cited 2021 Jan 26]. Available from: https://covid19. go.id/p/berita (Indonesian).

3. World Health Organization. Overview of public health and social measures in the context of COVID-19; 2020 May 18 [cited 2021 Jul 21]. Available from: https://apps.who.int/iris/rest/bitstreams/1278127/retrieve.

4. Badan Pemeriksa Keuangan Republik Indonesia. Concerning large-scale social restrictions (PSBB) in the context of accelerating the handling of coronavirus disease 2019 (COVID-19); 2020 [cited $2021 \mathrm{Jul}$ 21]. Available from: https://peraturan. bpk.go.id/Home/Details/135059/pp-no-21-tahun-2020 (Indonesian).

5. Ministry of Health of the Republic of Indonesia. Concerning guidelines for large-scale social restrictions in the context of accelerating the handling of coronavirus disease 2019 (COVID-19); 2020 [cited 2021 Jul 21]. Available from: http://hukor. kemkes.go.id/uploads/produk_hukum/PMK_No__9_Th_ 2020_ttg_Pedoman_Pembatasan_Sosial_Berskala_Besar_ Dalam_Penanganan_COVID-19.pdf(Indonesian).

6. Arifin C. PSBB enforcement in the Bogor, Depok and Bekasi regions starting Wednesday or Thursday. Tribunnews; 2020 Apr 12 [cited 2020 May 1]. Available from: https://www.tribunnews.com/nasional/2020/04/12/pemberlakuan-psbb-diwilayah-bogor-depok-dan-bekasi-dimulai-rabu-atau-kamis? _ga $=2.73185043 .1898280621 .1627207867-1181169301$. 1627207862 (Indonesian).

7. Kurniawan A, Rachmawati T, Fitriani Y, Nantabah ZK, Nuraini S, Agustya $R$, et al. Study of community compliance with appeals to stay distance and clean living behaviors during the COVID-19 pandemic; 2020 [cited 2021 Jul 21]. Available from: https://www.humanitarianresponse.info/sites/www.humani- tarianresponse.info/files/documents/files/paparan_hasil_survey_kepatuhan_150420.pdf (Indonesian).

8. Briscese G, Lacetera N, Macis M, Tonin M. Expectations, reference points, and compliance with COVID-19 social distancing measures; 2020 [cited 2021 Jul 21]. Available from: https:// www.nber.org/papers/w26916.

9. Government of Canada. From risk to resilience: an equity approach to COVID-19; 2020 [cited 2021 Feb 1]. Available from: https://www.canada.ca/en/public-health/corporate/publications/chief-public-health-officer-reports-state-public-healthcanada/from-risk-resilience-equity-approach-covid-19.html.

10. Marmot M, Wilkinson R. Social determinant of health. 2nd ed. Oxford: Oxford University Press; 2006, p. 376.

11. Hamilton K, Helliwell J, Woolcock M. Policy research working paper 7707. Social capital, trust, and well-being in the evaluation of wealth; 2016 [cited $2021 \mathrm{Jul}$ 21]. Available from: https:// openknowledge.worldbank.org/bitstream/handle/10986/ 24624/Social0capital0evaluation0of0wealth.pdf;sequence $=1$.

12. Murayama H, Fujiwara Y, Kawachi I. Social capital and health: a review of prospective multilevel studies. J Epidemiol 2012; 22(3):179-187.

13. Story WT. Social capital and health in the least developed countries: a critical review of the literature and implications for a future research agenda. Glob Public Health 2013;8(9): 983-999.

14. Candra AF. Social capital in a pandemic. Sindo News; 2020 Jun 2 [cited 2021 Feb 1]. Available from: https://nasional.sindonews.com/read/55413/18/modal-sosial-dalam-pandemi1591052807 (Indonesian).

15. Eriksson M. Social capital and health--implications for health promotion. Glob Health Action 2011;4:5611.

16. Arianto $K$, Fitriana EN. Social capital in community independence in the health sector. J Public Policy Adm 2013;17(2):3749 (indonesian).

17. Brodeur A, Grigoryeva I, Kattan L. Stay-at-home orders, social distancing, and trust. J Popul Econ 2021. doi: https://doi.org/ 10.1007/s00148-021-00848-z.

18. Kooistra EB, Reinders Folmer C, Kuiper ME, Olthuis E, Brownlee $M$, Fine, A, et al. Mitigating COVID-19 in a nationally representative UK sample: personal abilities and obligation to obey the law shape compliance with mitigation measures. SSRN 2020. doi: http://dx.doi.org/10.2139/ssrn.3598221.

19. Kuiper ME, de Bruijn AL, Reinders Folmer C, Olthuis E, Brownlee $M$, Kooistra EB, et al. The intelligent lockdown: compliance with COVID-19 mitigation measures in the Netherlands. SSRN 
2020. doi: http://dx.doi.org/10.2139/ssrn.3598215.

20. Oosterhoff B, Palmer CA. Attitudes and psychological factors associated with news monitoring, social distancing, disinfecting, and hoarding behaviors among US adolescents during the coronavirus disease 2019 pandemic. JAMA Pediatr 2020; 174(12):1184-1190.

21. Pedersen MJ, Favero N. Social distancing during the COVID-19 pandemic: who are the present and future non-compliers? Public Adm Rev 2020. doi: http://dx.doi.org/10.1111/puar. 13240.

22. Fancourt D, Bu F, Wan Mak H, Steptoe A. Covid-19 social study: results release 9; 2020 Sep 26 [cited 2021 Feb 1]. Available from: http://allcatsrgrey.org.uk/wp/wpfb-file/3d9db5_cf6736fab93e4fb898d42d8668a350a6-pdf/.

23. Moore RC, Lee A, Hancock JT, Halley M, Linos E. Experience with social distancing early in the COVID-19 pandemic in the United States: implications for public health messaging. medRxiv 2020. doi: http://dx.doi.org/10.1101/2020.04.08.20057067.

24. Raude J, Lecrique JM, Lasbeur L, Leon C, Guignard R, du Roscoät $E$, et al. Determinants of preventive behaviors in re- sponse to the COVID-19 pandemic in France: comparing the sociocultural, psychosocial, and social cognitive explanations. Front Psychol 2020;11:584500.

25. Fine A, Thomas A, van Rooij B, Cauffman E. Age-graded differences and parental influences on adolescents' obligation to obey the law. J Dev Life Course Criminol 2020;6:25-42.

26. Bansal G, Hodorff K, Marshall K. Moral beliefs and organizational information security policy compliance: the role of gender. Proceedings of the Eleventh Midwest United States Association for Information Systems; 2016 [cited 2021 Feb 1]. Available from: https://aisel.aisnet.org/cgi/viewcontent.cgi?article $=1011 \&$ context $=$ mwais 2016 .

27. Galasso V, Pons V, Profeta P, Becher M, Brouard S, Foucault M. Gender differences in COVID-19 attitudes and behavior: panel evidence from eight countries. Proc Natl Acad Sci U S A 2020; 117(44):27285-27291.

28. Liu J, Tong Y, Li S, Tian Z, Lu H, Zheng J. Compliance with COVID-19-preventive behaviours among employees returning to work in the post-epidemic period. Res Sq 2020. doi: https:// doi.org/10.21203/rs.3.rs-40330/v1. 